\title{
DA ESFERA PÚBLICA À PRIVADA: COMPREENSÕES DO ES- PAÇO FEMININO NA OBRA “A CONDIÇÃO HUMANA” DE HANNAH ARENDT
}

Arlen Maia de MELO'

Cris Érica Mendonça dos SANTOS ${ }^{2}$

Fabiana Costa KAMEYAMA

Mayara Haydeé Lima SENA

Sara Coelho de LIMA ${ }^{5}$

Marcos dos Reis BATISTA ${ }^{6}$

\begin{abstract}
RESUMO
O presente trabalho apresenta um estudo acerca do espaço feminino, atrelado aos conceitos de esfera pública e privada propostos pela filósofa Hannah Arendt, em sua obra A Condição Humana (1958). O objetivo deste estudo consiste em destacar a importância de sua obra conciliadas à relação de poder estabelecida sobre a figura da mulher e abordar sua relação no âmbito social através das representatividades de movimentos feministas. Os pensamentos do filósofo francês Michel Foucault (2014), assim como, os trabalhos contemporâneos de Judith Butler (2003) sobre as questões de gênero e sexualidade servem de base teórica para este trabalho. O subsídio para o desenvolvimento desta tarefa consiste na leitura reflexiva entre a obra de Arendt em diálogo com o pensamento destes teóricos. A autora aborda as questões sobre representatividade da figura feminina e seu posicionamento enquanto sujeito social, entendida como pertencente apenas à esfera privada e essa construção do feminino é tida assim como uma produção social, ou seja, é um ato intencionalmente construído ao longo dos anos. Nesse sentido, verifica-se o contexto real de privação proposto por Arendt na medida que a mulher é vista apenas como a rainha do lar, restringida de direitos e papéis sociais reforçando a ideia da ideologia da domesticidade propagada no século XIX e, direcionando o universo feminino ao verdadeiro sentido que é o de privação.
\end{abstract}

Palavras-chave: Feminino. Público-Privado. Gênero. Sexualidade.

\begin{abstract}
This paper presents a study about the feminine space, linked to the concepts of public and private sphere proposed by the philosopher Hannah Arendt, in her work The Human Condition (1958). The aim of this study is to highlight the importance of her work reconciled with the relation of power established on the figure of women and to approach their relationship in the social scope through the representations of feminist movements. The thoughts of the French philosopher Michel Foucault (2014), as well as Judith Butler's (2003) contemporary works on gender and sexuality, serve as the theoretical basis for this work. The subsidy for the development of this task consists in the reflexive reading between the work of Arendt in dialogue with the thought of these theorists. The author discusses questions about the representativeness of the female figure and her position as a social subject, understood as belonging only to the private sphere and this construction of the feminine is considered as a social production, in other words, an act intentionally built over the years. In this sense, the real context of deprivation proposed by Arendt is verified insofar in that the woman is seen only as the housewife, restricted in rights and social roles reinforcing the idea of the domesticity ideology propagated in the nineteenth century and directing the universe feminine to the true sense of deprivation.
\end{abstract}

Keywords: Female. Public-Deprived. Genre. Sexuality.
1 Graduando do Curso de Le- tras UFPA;

tras UFPA; 5 Graduando do Curso de

2 Graduando do Curso de Le- Letras UFPA;

tras UFPA;

3 Graduando do Curso de Le- 6 Mestre em Letras (Linguístras UFPA;

4 Graduando do Curso de Le- línguas, Universidade Fede- ral do Pará (UFPA), docente de Linguística e Linguística aplicada da Universidade Federal do Sul e Sudeste do Pará (UNIFESSPA)
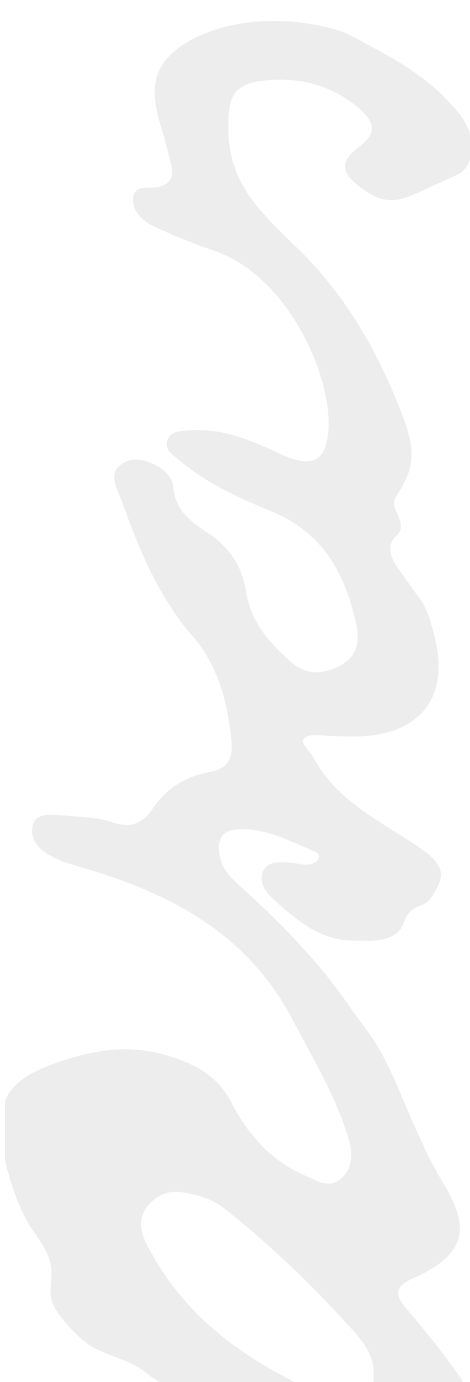
\section{.}




\section{CONSIDERAÇÕES INICIAIS}

Este trabalho surgiu a partir do interesse acerca das reflexões referentes aos estudos de gênero e sexualidade no âmbito do curso de Letras- Língua Portuguesa do Campus Universitário de Castanhal da Universidade Federal do Pará (UFPA). O objetivo deste estudo é de apresentar as contribuições desenvolvidas pela filósofa Hanna Arendt, em sua obra intitulada A condição Humana ${ }^{7}$ (2007), - com ênfase para os estudos do espaço feminino - e, além disso, enfatizar a importância sobre o posicionamento do sujeito frente à sociedade e sua influência na contemporaneidade. Para tanto, tomamos como embasamento teórico os textos de Foucault (2015), Butler (2003).

Nossa intenção aqui partiu, também, das observações feitas em leituras de outros textos que deram suporte à presente investigação que colocam em voga o papel central da mulher na sociedade; mostrando avanços, conquistas e direitos que foram adquiridos por meio de lutas sociais entre outros fatores.

Este trabalho desdobra-se nos seguintes objetivos específicos, a saber:

1) Dialogar acerca da importância dos textos de Arendt (2007), proporcionando uma reflexão com as teorias de Foucault ${ }^{8}$ (2015) e Butler (2003) em uma leitura analítica embasada nos conceitos de esfera pública e privada em sua obra A condição Humana;

2) Atrelar os questionamentos sobre espaço feminino tratados pela autora em sua produção intelectual, relacionando-o à sociedade disciplinadora e o controle-corpo propostos por Michel Foucault (2015) e;

3) Dialogar, a partir disso, com teóricos e estudiosos sobre os assuntos referentes ao feminino e às questões de gênero.

Este trabalho divide-se em três seções, no primeiro momento se discorre acerca do conceito de Esfera Pública, abordado pela autora, enfatizando também seu posicionamento acerca do espaço político e a invisibilidade feminina. Posteriormente, discorre-se sobre o Espaço Privado - em seu sentido real de privação - segundo Arendt, no qual a mulher está inserida, e, por fim, realiza-se alguns apontamentos

7 Para este trabalho faz-se uso da tradução publicada no ano de 2007 (Editora Forense Universitária) por Roberto Raposo para a língua portuguesa da obra A Condição Humana de Hannah Arendt originalmente lançada em 1958.

8 Para este trabalho faz-se uso da tradução para a língua portuguesa publicada no ano de 2015 pela Editora Paz e Terra da obra Microfísica do Poder.

9 Apresentam-se aqui as concepções de Esfera Pública e, posteriormente, de Esfera Privada, abordadas pela filósofa Hannah Arenth em sua obra A Condição Humana (2007),analisada através da tradução de Roberto Raposo (2007)indicada detalhadamente nas referências desse trabalho. importantes acerca das questões de gênero e as diversas formas de repressão e enquadramento do sujeito feminino na sociedade.

\section{A ESFERA PÚBLICA: O COMUM ${ }^{9}$}

De acordo com a obra de Arendt - A Condição Humana (2007) - encontra-se a conceituação de duas esferas em que o homem está inserido, são elas: a esfera pública: o comum, aqui, considera-se o espaço onde o indivíduo apresenta uma voz que é expressada e é notoriamente escutada, abrangendo um alcance considerável em caráter social e a esfera privada: a propriedade - neste ponto, tratada em sentido de 'privação', destituição da vida pública.

As contribuições de Arendt de esfera pública, trazendo para o âmbito deste trabalho, são tratadas aqui para observar essa relação equivalente com a obra de Butler Problemas de gênero - Feminismo e subversão da identidade (2003). Assim sendo, a abordagem de Butler em seu primeiro capítulo refere-se à apresentação da mulher enquanto sujeito do feminismo, aqui remetendo à representação social, posicionamento político e ideológico, caracterizando não um corpo maleável, domável, muito menos denominado de sexo frágil; mas, sim, desencadeando uma postura transgressora aos modelos patriarcais dominadores. Explicita-se aqui as concepções de Arendt acerca da esfera pública:

Uma vez que a nossa percepção da realidade depende totalmente da aparência, e, portanto, da existência de uma esfera pública na qual as coisas possam emergir da treva da existência resguardada, até mesmo à meia-luz que ilumina a nossa vida privada é intima deriva, em última análise da luz muito 
mais intensa da esfera pública. No entanto, há muitas coisas que não podem suportar a luz implacável e crua da constante presença de outros no mundo público; neste, só é tolerado o que é tido como relevante, digno de ser visto e ouvido, de sorte que o irrelevante se torna automaticamente assunto privado. (ARENT, 2007, p. 61).

A mulher nesse aspecto é detida de seu posicionamento social, restituída apenas à vida doméstica e às tarefas do lar. Neste caso, à vida privada, cabe ao homem lidar com a vida em seu ambiente público, realizando tarefas que condizem com sua masculinidade e, estando centrado no exercício de sua racionalidade como se a conjectura feminina fosse desprovida de razão. Nesse contexto, afirma Arendt que, o privado ainda reside às trevas; com isso, cabe à mulher, portanto, atravessar esse contingente para, então, pertencer à luz, entendida nesse caso como razão.

Nem sempre as questões privadas, partindo do exposto, constituem uma inutilidade. Afinal, sempre há espaço para todos nesse mundo, mesmo que esse 'todo' seja na maioria das vezes ignorado, silenciado e destituído de seu posicionamento social. A importância da esfera privada só é evidenciada na medida em que o público necessita, por assim dizer, de uma contraposição. Assim sendo: “[...] O amor, por exemplo, em contraposição à amizade, morre, ou antes se extingue assim que é trazido ao público [...]" (ARENDT, 2007, p. 61).

É importante frisar a grande desigualdade que ainda predomina na sociedade em relação ao feminino e masculino perpassando grandes momentos da história social. A violência, a intolerância e a repressão, acabam por ocasionar a invisibilidade feminina na sociedade, apoiada pela presença ainda sólida da cultura patriarcal. As diversas formas de opressão acometidas ao feminino também acabam por resultar em sua falta de liberdade enquanto sujeito e, sendo privada até mesmo em relação à sua sexualidade.

O controle do corpo feminino está sujeito às regras estabelecidas, tanto para a esfera pública, por fatores ideológicos como o estado, a igreja, etc., ou qualquer forma de poder que é estabelecida, quanto pela esfera privada - seio familiar, matrimonial - moldando seus comportamentos, sendo de certa forma adestrada a assumir certos posicionamentos desde a infância. As regras apontadas para repressão da sexualidade feminina consistem na apropriação do sexo atrelando-o à prostituição, a mulher da vida, ou mulher pública, e, sendo este um modo de reprimir e diminuir a condição feminina contrariando o modelo dito 'normal' que trata a mulher como 'recatada e do lar' centrada principalmente na vida doméstica e nos cuidados com os filhos.

A identidade feminina, que é difundida pelos movimentos de luta está suportada em interesses políticos que exigem representatividade. Com isso, pressupõe-se que as lutas dos movimentos feministas estão cada vez mais intensas e frequentes, propagando ideais de conquistas que os foram negados até então. Sendo assim Butler (2003) considera que:

Em sua essência, a teoria feminista tem presumido que existe uma identidade definida, compreendida pela categoria de mulheres que não só deflagra os interesses e objetivos feministas no interior de seu próprio discurso, mas constitui o sujeito mesmo em nome de quem a representação política é almejada [...]. Por um lado, a representação serve como termo operacional no seio de um processo politico que busca estender visibilidade e legitimidade às mulheres como sujeitos políticos; por outro lado, a representação é a função normativa de uma linguagem que revelaria ou distorceria o que é tido como verdadeiro sobre a categoria das mulheres. (BUTLER, 2003, p. 17-18)

Entende-se, desse modo, a representatividade feminina como a legitimação VOL. 14 | N.2 | DEZ. 2017 
do ser feminino diante da complexidade social alimentando, ainda, a ideia de subespécie como condição pertinente em um mundo totalmente patriarcal.

\section{A ESFERA PRIVADA: A PROPRIEDADE}

O espaço feminino tem sido alvo de disputa ao longo do tempo, através de muitas lutas e conquistas com o apoio e articulação de grupos e determinados movimentos sociais. Nesse sentido, o papel concedido à figura da mulher sempre visava o âmbito familiar, a relação doméstica e a responsabilidade nos cuidados com os filhos. De acordo com Arendt (2007), a mulher constituía-se em um espaço privado, porém, em seu sentido real de privação. Com isso, não poderia participar no mundo público no qual o homem era considerado o detentor estabelecido nesse meio através do processo político e ideológico que permeia a sociedade. Desse modo, essa relação entre o público e o privado se manifesta por meio da articulação dos papeis sociais atribuídos à mulher e o homem ao decorrer da história. Assim, ela o conceitua do seguinte modo:

É em relação a essa múltipla importância da esfera pública que o termo 'privado', em sua acepção original de 'privação' tem significado. Para o individuo, viver uma vida inteiramente privada significava, acima de tudo, ser destituido de coisas essenciais à vida verdadeiramente humana: ser privado da realidade que advém do fato de ser visto e ouvido por outros, privado de uma relação 'objetiva' com eles decorrente do fato de ligar-se e separar-se deles mediante um mundo comum de coisas, e privado da possibilidade de realizar algo mais permanente que a própria vida. A privação da privatividade reside na ausência de outros; para estes, o homem privado não se dá a conhecer, e, portanto, é como se não existisse. O que quer que ele faça permanece sem importância ou consequência para os outros, e o que tem importância para ele é desprovido de interesse para os outros. (ARENDT, 2007 p. 68).

A preocupação na vida escolar ainda com os estudos de sexualidade se prendem ao temor da homossexualidade permitindo assim, o desencadeamento de vários estudiosos acerca da temática de gênero. A proposição da aplicação de disciplinas que normatizam o indivíduo são elementos de correção que ainda persistem em modelos escolares, cabendo ao profissional da educação favorecer a inclusão e, a permanência das variadas manifestações de gênero no âmbito escolar.

Os espaços para discussão de sexualidade, gênero e perspectivas da Teoria Queer ${ }^{10}$ estão cada vez mais frequentes no Brasil. Portanto, ainda há um certo estigma e, não obstante, preconceito, em tratar desses questionamentos. É necessário se pensar a Teoria Queer em uma disposição política e social. No entanto, não nos prenderemos nesta temática na presente contribuição pois trata-se de uma teoria - ou

10 Segundo Butler, o termo tem operado uma prática linguística com o propósito de degradar os sujeitos aos quais se refere. 'Queer adquire todo o seu poder precisamente através da invocação reiterada que o relaciona com acusações, patologias e insultos' (2003, p. 58).

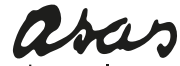

\begin{tabular}{l|l|l|l} 
VOL. 14 & N.2 & DEZ. 201'
\end{tabular} da palavra ISSN 1415-7950 quem sabe, de um estudo - para um debate a ser cada vez mais ampliado no meio acadêmico.

O poder de representação sobre os meios de comunicação, entre eles a tv, cinema, internet ou outras mídias, caracterizam uma centralização desse controle. As demonstrações de afeto na vida pública entre casais homoafetivos, por exemplo, ainda é vedada e é motivo de repressão; disseminando com isso, a recusa da execução de determinada sexualidade. Não importando o que o indivíduo faça, mas sim, que não seja levado à esfera pública. As variedades culturais influenciam diretamente em um processo de modificação de valores, concepções e ideologias que colaboram com a construção de modelos e, estabelecem, assim, padrões sociais.

Nesse âmbito, se a mídia influencia diretamente a sociedade, transgredindo, com isso, o 'modelo social padrão' espera-se assim, um posicionamento em relação 
aos problemas sociais. Desse modo, a importância do sujeito deve ser exercida em todas as esferas sociais, rompendo preconceitos e considerando importante os debates de gênero e sexualidade.

\section{DEBATES EM TORNO DA QUESTÃO DE GÊNERO}

A noção de gênero segundo Butler não deve ser entendida como um atributo fixo de uma pessoa, mas como uma variável fluída, apresentando diferentes configurações. Nesse âmbito, os estudos de Louro (2000) enaltecem essa afirmativa na medida que apresentam a noção de sexualidade como sentido universal.Com isso, afirma:

\begin{abstract}
[...] A sexualidade seria algo 'dado’ pela natureza, inerente ao ser humano. Tal concepção usualmente se ancora no corpo e na suposição de que todos vivemos nossos corpos, universalmente, da mesma forma. No entanto, podemos entender que a sexualidade envolve rituais, linguagens, fantasias, representações, símbolos, convenções... Processos profundamente culturais e plurais [...]. Os corpos ganham sentido socialmente. A inscrição dos gêneros - feminino ou masculino — nos corpos é feita, sempre, no contexto de uma determinada cultura e, portanto, com as marcas dessa cultura. As possibilidades da sexualidade - das formas de expressar os desejos e prazeres também são sempre socialmente estabelecidas e codificadas. As identidades de gênero e sexuais são, portanto, compostas e definidas por relações sociais, elas são moldadas pelas redes de poder de uma sociedade. (LOURO, 2000.p. 5-6)
\end{abstract}

Assim sendo, a partir destas concepções de Louro acerca do corpo e o poder que é exercido sobre ele, constata-se sua estreita relação com o pensamento foucaultiano sobre o Biopoder. Considerando, desse modo, o corpo como objeto de manipulação - o que Foucault denomina corpos dóceis - na qual esse poder é exercido, toda forma de transgressão às leis impostas aos corpos refletem uma adequação quase que imediata - das formas de inserção desse poder. Conforme é observado nas palavras de Foucault:

O Corpo se tornou aquilo que está em jogo numa luta entre os filhos e os pais, entre as crianças e as instâncias de controle. A revolta do corpo sexual é o contra efeito dessa ofensiva. Como é que o poder responde? Por meio de uma exploração econômica (e talvez ideológica) da erotização, desde os produtos para bronzear até os filmes pornográficos...Como resposta à revolta do corpo, encontramos um novo investimento que não tem mais a forma de controle-repressão, mas de controle-estimulação: 'Fique nu...mas seja magro, bonito, bronzeado!' A cada movimento de um dos dois adversários corresponde o movimento do outro. (FOUCAULT, 2015, p.236).

A terminologia Biopoder foi utilizada por Foucault para designar atribuição a ação do estado sobre o indivíduo caracterizando a realização do poder disciplinar tornando, assim, cada corpo humano dócil e produtivo. As diversas formas de estabelecimento dessa realização do poder-corpo. Com isso, esse poder referido por Foucault não é exercido de fato pelo sujeito, mas, sim, por uma sistemática ideológica através de ações estatais que visam definir uma padronização social desconsiderando a individualidade do sujeito. Por isso, o autor destaca que: 
O que eu gostaria precisamente de mostrar, em relação a tudo que atualmente se diz a respeito da liberação da sexualidade, é que o objeto sexualidade é, na realidade, um instrumento formado há muito tempo e que se constitui como um dispositivo de sujeição milenar. O que existe de importante nos movimentos de liberação da mulher não é a reivindicação da especificidade da sexualidade e dos direitos referentes a esta sexualidade especial, mas o fato de terem partido do próprio discurso que era formulado no interior dos dispositivos de sexualidade. ((FOUCAULT, 2015, p. 395)

Por fim, entende-se através das palavras de Foucault que a sexualidade muito mais do que uma polêmica, ela é por si só um instrumento que constitui um sujeitamento do indivíduo no meio social. Em outras palavras, uma mecanização da ação estatal para que os corpos sejam manipulados de modo sistemático desconsiderando sua individualidade buscando um controle maior sobre seus cidadãos.

Teresa de Lauretis (1994) atenta a limitações no conceito recorrente da "diferença sexual" nas investigações feministas, o qual compreende a mulher dessemelhante à figura do homem, "ou seja, a própria diferença no homem" (LAURETIS, 1994, p. 207). Nesta perspectiva, a autora chama a atenção para uma grande limitação no conceito de "diferença(s) sexual(ais)", que configura-se na ideia de que a mulher, como diferente do homem (e sempre partindo do modelo deste) é, assim como o homem, universalizada. Como ambos são generalizados, as mulheres seriam uniformemente iguais e "não haveria absolutamente qualquer diferença e todas as mulheres seriam ou diferentes personificações de alguma essência arquetípica da mulher, ou personificações mais ou menos sofisticadas de uma feminilidade metafísico-discursivo" (LAURETIS, 1994, p. 207). Para estes e outros problemas, a autora tenta postular um conceito de gênero que ultrapasse a ideologia de diferença sexual, mas não se separe totalmente desta, e que consiga abarcar um sujeito múltiplo. E a partir das considerações foucaultianas sobre sexualidade, constrói uma teoria do gênero que entende "o gênero como um produto e processos de um certo número de tecnologias sociais ou aparatos biomédicos” (LAURETIS, 1994, p. 208). Suas hipóteses são de que "O gênero é (uma) representação [...] A representação do gênero é sua construção [...] A construção do gênero vem se efetuando hoje no mesmo ritmo de tempos passados [...] a construção do gênero também se faz por meio de sua desconstrução" (LAURETIS, 1994, p. 209).

Com base, nessa discussão podemos entender que a desconstrução não se trata de um apagamento do que foi pensando, refletido, conceituado e/ou afirmado em tempos anteriores. Mas, uma mudança de foco, de possíveis parâmetros e reflexões diante dos diferentes aspectos, características e fenômenos existentes que acompanham as mudanças sociais; assim, como novas e velhas demandas da sociedade em si. Mudanças ou desconstruções passam pelo viés do polêmico, da desconfiguração, da desestabilização do paradigma. Toda essa discussão desemboca nas lutas sociais por direitos. Direitos, esses, que para grupos majoritários politicamente falando são vistos como 'possíveis' privilégios. No entanto, essa luta por direitos gira em torno, justamente, das comparações entre homens e mulheres. Conforme afirmado acima, a busca por direitos feministas parte, geralmente, da dicotomia, homem versus mulher. Percebe-se, com isso, que as discussões e/ou reflexões ainda estão presas na construção feminina partindo do homem. Ainda se ressente de uma problematização acerca do papel feminino - se é que se pode pensar em 'papel' de um modo singular, e não, plural - no âmbito da contemporaneidade líquida (BAUMAN, 2001) que desconstrói toda uma visão concreta, consolidada, fixa e consistente dos papeis sociais ao afirmar que a durabilidade das relações e de outros tantos comportamentos no chamado globalizado não são mais rígidas como em tempos atrás. 


\section{CONSIDERAÇÕES FINAIS}

Diante do exposto, o presente trabalho, que ainda se encontra em seu estágio primário, se mostra propulsor no que tange aos nossos estudos acerca do papel social da mulher e seu espaço em meio à discussões propostas por Hanna Arendt colaborando significativamente com nossas reflexões educacionais/formativas e com nossa prática docente no que trata, principalmente, a condição feminina. Nesse entendimento, considera-se seus aprofundamentos teóricos e estudos ora tratados como inovadores e precursores do cenário contemporâneo, sendo sua produção cada vez mais debatida e estudada nas demais áreas do conhecimento. Além disso, suas contribuições colocam em pauta vários aspectos sociais, como a desconstrução de preconceitos, estereótipos e atitudes machistas que ainda predominam na sociedade.

A igualdade de gênero demonstra e fortalece a ideia de que todos os seres humanos, tanto mulheres como homens, são livres para desenvolver as suas capacidades pessoais, destituídos de qualquer elemento normatizador e fazer escolhas sem as limitações impostas por estereótipos. Para tanto, igualdade de gênero não significa que as mulheres e homens têm de ser idênticos, mas que a partir da preservação de seus direitos, responsabilidades e oportunidades não dependem de uma normatização que os coloquem como marionetes a mercê do controle estatal. A equidade, com isso, entre gêneros significa que homens e mulheres são tratados de forma justa, de acordo com as respectivas necessidades e características. Desse modo, o tratamento deve considerar, valorizar e favorecer de maneira equivalente os direitos, benefícios, obrigações e oportunidades entre ambos os gêneros.

Por fim, nossas reflexões à base de Arendt, ainda que primárias, apontam para a necessidade de estudos e reflexões cada vez mais ampliadas visando uma análise da condição humana buscando por meio da educação - que é o nosso âmbito profissional e formal - ações que colaborem com a construção de uma sociedade na qual homens e mulheres possam ser, de fato, agentes com os mesmos direitos e deveres constituindo com isso, uma própria e real sociedade contemporânea.

\section{REFERÊNCIAS}

ARENDT, Hannah. Tradução de Roberto Raposo. A Condição Humana. Rio de Janeiro: Forense Universitária, 2007.

BAUMAN, Zygmunt. Modernidade líquida. Rio de Janeiro: Zahar, 2001.

BUTLER, Judith, P. Problemas de gênero - Feminismo e subversão da identidade. Rio de Janeiro: Civilização Brasileira, 2003.

FOUCAULT, Michel. Microfisica do poder. Rio de Janeiro: Paz e Terra, 2015.

LAURETIS, Teresa. In: HOLLANDA, Eloisa Buarque de (org.). Tecnologia do gênero tendências e impasses - O feminismo como crítica da cultura. Rio de Janeiro: Rocco, 1994. p. 204-242.

LOURO, Guacira, L. O corpo educado: pedagogias da sexualidade. Belo Horizonte: Autêntica, 2000. 